\title{
Implementation of 5S in the Pantry Housekeeping of Hotels to Increase Work Productivity
}

\author{
M. Yusuf ${ }^{1}$, N.K. Dewi Irwanti ${ }^{2}$ \\ Politeknik Negeri Bali, Bali Indonesia ${ }^{1}$ \\ STIPAR Triatma Jaya Denpasar, Bali Indonesia ${ }^{2}$ \\ $\left\{\right.$ yusuf@pnb.ac.id $\left.{ }^{1}\right\}$
}

\begin{abstract}
Housekeeping possessed warehouse storage of goods, including parts pantry (Floor Station). A place to store this stuff if not managed properly then it will be their own complaint for both workers and management. Complaints that arise usually messy stuff, stuff that in looking for difficult to reach, absence and so that adds to the workload of complaints and its own for house keeping part of the hotel employees. To provide solutions to the problems, conducted experimental research is the implementation of 5S (Seiri, Seiton, Seiso, Seiketsu, Shitsuke) or also called 5R (Ringkas, Rapi, Resik, Rawat, Rajin). This research was conducted at four hotels in Kuta, Bali with 20 employees as sample, and treatment by subject design. The musculoskeletal disorder predicted by Nordic Body Map questionnaire, fatigue is predicted by 30 item questionnaire general fatigue, and work productivity predicted by work volume divided by workload and work time. Data were analyzed at the level of significance of $5 \%$. Result of analysis showed that between before and after treatment $5 \mathrm{~S}$ increase significantly $(\mathrm{P}<0.05)$ on the musculoskeletal disorders (25.4\%), general fatigue $(28,4 \%)$, and increase productivity $(32,5 \%)$. It was concluded that the implementation of $5 \mathrm{~S}$ can increase work productivity workers hotel.
\end{abstract}

Keywords: Implementation of 5S, Musculoskeletal disorder, General Fatigue, Work Productivity

\section{Introduction}

Housekeeping is a part of the hotel that has an important role in running the hotel hygienic and sanitation program properly and implementing safety and security procedures for workplaces, colleagues and hotel guests.

The function of housekeeping is to create cleanliness in the hotel area, especially rooms that are superior products, maintain facilities / equipment so that they can last a long time and can always function properly, equipment is always clean and can be used properly, makes it easy for guests to use it, makes guests feel comfortable, and feel at home living in a hotel. Housekeeping also carries out maintenance inside and outside the building properly and systematically, including creating and maintaining cleanliness, tidiness, beauty and comfort, 
providing facilities and providing services to consumers in accordance with standard operating procedures in hotels.

Hotels are one of the supporting factors for tourism has a very important role in developing tourism facilities and infrastructure. Hotels as a type of accommodation are directly involved in providing lodging, eating and drinking services and other facilities which are expected to provide satisfaction for everyone who uses these services. Hotels in Kuta Bali have many facilities. Usually more than 100 rooms of various types can be used by hotel guests, Meeting Room facilities, Business Centre, Restaurant \& Bar, Beach Pizza, Sunken Bar, Spa, Swimming Pool, Medical Assistance, Baby Sitting, Garden, Free Wi-Fi in the room \& hotel area, and others. All of these facilities need equipment for handling and maintenance. Equipment is usually stored in the pantry.

Management of equipment and materials management is a separate problem for each hotel. Handlers who do not use good management will make stored items disorganized, pile up, and provide additional work fatigue for hotel employees in the pantry department.

Pantry is a room for Housekeeping to store, organize, arrange trolly charts in cleaning guest rooms. This pantry functions as a store line where all the amenities for guest rooms, ranging from bed facilities, bathroom facilities, living room facilities and other amenities are stored and arranged according to stock. Pantry cleanliness must be maintained as well as possible, each pantry is equipped with its own staff.

The problems that occur are the lack of organization of the existing items which causes additional morning burden for employees / pantry staff, slower work, equipment does not look neat, and causes work accidents. Lack of pantry handling management can increase subjective complaints among employees. These subjective complaints are musculoskeletal disorders and general fatigue. Fatigue and musculoskeletal disorders are ergonomic problems that are often found in the workplace. That problems cause employees to be unable to work effectively, safely, comfortably and healthily. In the hospitality industry, problems related to fatigue and complaints of skeletal muscles are problems that are often experienced by employees, especially hotel stewards. A study mentioned that $91 \%$ of flight attendants experience complaints of musculoskeletal while working [1].

To provide solutions to these problems, an experimental research was carried out, namely the implementation of 5S (Seiri, Seiso, Seiton, Seiketsu, Shitsuke) or also called 5R in Indonesia (Ringkas, Rapi, Resik, Rawat, Rajin) to facilitate and simplify the work process of the pantry house section. keeping. $5 \mathrm{~S}$ is a very simple concept so that it can be easily understood and implemented by anyone. But it is very difficult to apply it correctly, this is because of our habit of wanting to be happy on our own and do not want to be bound by existing rules. $5 \mathrm{~S}$ is the first step of continuous improvement (Kaizen). The $5 \mathrm{~S}$ can be used as a management barometer. $5 \mathrm{~S}$ operates on the principle of "deeds are more convincing than words". 5S changes the way of thinking and behaving A good system is not enough, but there must be a system that changes behavior to be responsible.

The benefits of implementing $5 \mathrm{R}(5 \mathrm{~S})$ in the workplace include: (1) Increasing productivity due to a more efficient workplace arrangement, (2) Increasing comfort because the workplace is always clean and becomes spacious / spacious, (3) Reducing hazards in the workplace because the quality of the workplace is good / good, (4) Increase savings by eliminating various waste in the workplace.

Implementation of $5 \mathrm{~S}$ is a technique from Japan developed in 1980s by Hiroyuki Hirano. $5 \mathrm{~S}$ is Japanese words, namely: Seiri, Seiso, Seiton, Seiketsu and Shitsuke (Sort, Shine, Set in order, Standardize and Sustain). The $5 \mathrm{~S}$ focuses on simplification of the effective workplace organization, reduction of waste while improving quality and safety, and work environment 
[2]. The first S (Seiri), Throwing away items that are not needed. The second S (Seiton), fixing and standardizing the place of storing / placing goods or equipment in its place. The third S (Seiso), keeping the workplace clean (cleaning the workplace so that it is free from dust and trash). The fourth S (Seiketsu), maintaining the workplace to keep it compact, clean / tidy and tidy. The fifth S (Shitsuke's), self-discipline. The 5S method can create a quality work environment that is clean, can ensure compliance with standards and will further promote continuous improvement, safe and comfortable [3].

The four steps taken in implementing $5 \mathrm{~S}$ at the Puri Sharon hotel are as follows (1) Recording the current situation so that it can be used as a comparison after carrying out $5 \mathrm{~S}$ activities (before and after), (2) Carrying out 5S activities, (3) Cultivating 5S, Make it 5S is an inseparable part of our daily work activities, (4) Re-evaluate $5 \mathrm{~S}$ and take preventive measures so that $5 \mathrm{~S}$ is maintained at work. From the description above, it is deemed necessary to measure the implementation of $5 \mathrm{~S}$ on the workload, general fatigue, and musculoskeletal disorders of employees in the pantry department at the Hotel, Kuta-Bali.

\section{Research Methods}

This research is an experimental research with design "treatment by subject". The sample used was 20 hotel employees in Kuta Badung, Bali, calculated based on the Pockok formula [4]. The variables in this study were the independent variables: namely the implementation of $5 \mathrm{~S}$, and the dependent variables: namely workload, general fatigue, and musculoskeletal disorders.

The workload is predicted from the employee's work rate, which is measured using a pulse meter. General fatigue were measured using 30 items of the general fatigue rating scale. While musculoskeletal disorders measured use a Nordic Body Map questionnaire. Productivity is measured from the comparison between the amount of work that can be completed with the work rate multiplied by the work time required. Each subject gets two periods, namely period one (P1) the subject does work without implementing 5S, and period two (P2) the subject does work with 5S implementation. Between P1 and P2 there was washing out for two days. The resulting data were analyzed using descriptive and inferential analysis with 5\% significance level or $\alpha=0.05$.

\section{Results and Discussion}

\subsection{Subject's Characteristics}

The subjects used in this study were 20 workers. The analysis results are presented in Table 1 below.

Table 1. Hotel Employee Characteristics Data

\begin{tabular}{lccc}
\hline \multicolumn{1}{c}{ Variable } & Mean & Deviation Standard & Range \\
\hline Age (years) & 28.47 & 5.40 & $23.00-36.00$ \\
Height $(\mathrm{cm})$ & 168.51 & 4.14 & $166.31-172.24$ \\
Weight $(\mathrm{kg})$ & 60.23 & 3.23 & $57.50-65.50$ \\
BMI & 22.13 & 1.32 & $20.31-23.19$ \\
Work Experience (years) & 4,52 & 0,18 & $2-8$ \\
\hline
\end{tabular}

Mark: BMI $=$ Body Mass Index 
The mean age of the subjects involved in this study was $28.47 \pm 5.40$ years with a range of 23 - 36 years. The average age is in the productive age range, where the subject can perform activities with optimal physical strength. Physical capacity reaches its peak at age 25 and is directly proportional to age to some extent [5]. Employee BMI (body mass index) is in the range of $20.31-23.19 \mathrm{~kg} / \mathrm{m} 2$ with a mean of $22.13 \pm 1.32 \mathrm{~kg} / \mathrm{m} 2$. The average BMI indicates that the subject's body condition is at normal limits, so that the subject's physical condition is in good health, there are no problems with nutrition, and can carry out activities optimally.

The condition of worker's body weight, body height, and body mass index were in normal condition category. Musculoskeletal disorders are also often at normal body mass index due to work factors [5]. Body mass index which is not normal will influence the person's workload. A worker who is too fat or too thin will be influenced by his/her physical condition when working. A fat worker is not agile when working because the weight of his/her body, thus too many movements will cause fatigue and decrease the productivity. In addition, smaller BMI will reduce the risk of disease and muscular complaints at workplace [6].

Over time, the condition of a person's age can affect the ability to work muscles and physical, maximum physical ability is reached between the ages of 25 to 35 years and will continue to decline with increasing age [5]. In human organ systems such as the respiratory, muscular, and cardiovascular after the age of 30 years it can decrease per year by about $2 \%$ [7]. The Age conditions can affect a person's muscle strength and physical work ability. Maximum physical ability for a person is reached between the ages of 25 to 35 years and will continue to decline with age. Based on the working experience shown on Table 1, it could be concluded that the worker were already expert at their skill. Working experience is one of many factors which influences the level of worker's skill, musculoskeletal complaints, and productivity [5].

\subsection{Environmental Conditions}

The working environment conditions in P1 (Period 1) and P2 (Period 2) were analyzed by using pair t-test. The analysis results are presented in Table 2.

Table 2. Environmental Conditions

\begin{tabular}{lcccccc}
\hline \multirow{2}{*}{ Variable } & \multicolumn{2}{c}{ P1 } & \multicolumn{2}{c}{ P2 } & \multirow{2}{*}{ t } & p \\
\cline { 2 - 5 } & Mean & SD & Mean & SD & & 0.097 \\
\hline Temperature $\left({ }^{\circ} \mathrm{C}\right)$ & 26.85 & 1.21 & 27.04 & 1.70 & 2.184 & 0.371 \\
Humidity $(\%)$ & 77.38 & 2.32 & 78.12 & 2.35 & 1.936 & 0.37 \\
Sound Intensity (db) & 61.24 & 3.47 & 60.89 & 3.32 & -1.341 & 0.269 \\
Light Intensity (luks) & 362.10 & 10.17 & 371.33 & 11.07 & 9.452 & 0.327 \\
\hline
\end{tabular}

Table 2 shows that there is no difference in the work environment conditions for P1 and P2 ( $p>0.05$ ), so it can be said that the environmental conditions for period 1 and period 2 are the same and do not affect the research interventions carried out.

This environmental condition is in a comfort zone, considering that the temperature of the comfort zone for Indonesians ranges from $22-28^{\circ} \mathrm{C}$. Soleman \& Sitania stated that the effective temperature for tropical areas is $22-27^{\circ} \mathrm{C}$ [6]. The upper limit for optimal comfort is $28^{\circ} \mathrm{C}$ and the relative humidity is $70 \%$ or $25.8^{\circ} \mathrm{C}$, the effective temperature lower limit is $24^{\circ} \mathrm{C}$ and the relative humidity is $80 \%$ or $22.8^{\circ} \mathrm{C}$ [8]. A job can be done well and comfortably if there is good lighting. When doing activities can see objects well, clearly, and quickly. Amount of light intensity for normal activities is 200 to 800 lux [9], and the lighting conditions in both periods are in accordance with the specified requirements. 


\subsection{WorkLoad}

The workload is one of the important factors to measure the weight of a task including hotel employee. The workload can be predicted from the frequency of heart rate of the employee because heart rate is one of indicators that can be used to decide the level of workload.

Workload is measured based on the employee's work pulse both at rest (resting pulse) and at work (work pulse). The data normality test was performed using the Kolmogorov-Smirnov $(\mathrm{K}-\mathrm{S})$ test. From the test, it was found that the resting pulse rate and working pulse rate in both treatments $(\mathrm{P} 0$ and $\mathrm{P} 1)$ were normally distributed $(\mathrm{P}>0.05)$. Before analysing the effects of the treatment, the comparability of the resting pulse rate is first performed. This is done to see whether the initial conditions of the employees are different or the same. This is necessary to see whether the change in workload is purely due to treatment effects or there are external factors that have contributed to the change in workload. The comparability of resting pulse rate and work pulse rate for employees was carried out using the t-pair test. The analysis results are presented in Table 3.

Table 3. Analysis of Employee Workload

\begin{tabular}{ccccccc}
\multicolumn{7}{c}{ Table 3. Analysis of Employee Workload } \\
\cline { 2 - 5 } Variable & \multicolumn{2}{c}{ P1 } & \multicolumn{2}{c}{ P2 } & t & p \\
\cline { 2 - 5 } & Mean & SD & Mean & SD & & \\
\hline Resting & 71.12 & 3.82 & 70.96 & 2.17 & -0.031 & 0.153 \\
pulse rate \\
$\quad$
\end{tabular}

Table 3 shows that the resting pulse rate in each period did not differ significantly $(\mathrm{p}>$ 0.05 ). This may imply that the initial conditions for the employee's resting pulse at each period can be considered the same. While the working pulse can be seen that there is a significant difference between $\mathrm{P} 1$ and $\mathrm{P} 2$ or $\mathrm{p}<0.05$. Judging from the mean, there is a decrease in the work pulse from 121.07 beats per minute to 115.37 beats per minute, or a decrease of $15.1 \%$. Based on the workload category, the workload is medium [5]. Evaluation of workload is important to be used as a basis for making interventions or improvements to the work system [10], [11].

\subsection{Musculoskeletal Disorders}

Musculoskeletal disorders in this research were measured using a Nordic Body Map questionnaire. The comparability test of skeletal muscle complaints was carried out using the Wilcoxon test, namely by comparing the average fatigue in period 1 with period 2 before working. The results of the analysis show on Table 4 below.

Table 4. Result of Musculoskeletal Disorders Analysis

\begin{tabular}{lcccccc}
\hline & \multicolumn{2}{c}{ Period 1 } & \multicolumn{2}{c}{ Period 2 } & \multirow{2}{*}{ Z } & \multirow{2}{*}{ P } \\
\cline { 2 - 5 } & Mean & SD & Mean & SD & & \\
\hline pre & 38,98 & 2,67 & 39,12 & 2,15 & 0,163 & 0,219 \\
post & 78,36 & 4,36 & 57,18 & 3,97 & $-12,426$ & 0,004 \\
\hline
\end{tabular}


Table 4 shows that there is no difference in the initial (pre) condition of the subject, while in the final (post) condition between $\mathrm{P} 1$ and $\mathrm{P} 2$ there is a significant difference $(\mathrm{p}<0.05)$. Between period 1 and period 2 there was a decrease in skeletal muscle complaints by $27.03 \%$. The decrease in musculoskeletal complaints due to more organized equipment arrangements and the unnatural work attitude of the employees was no longer present. Work posture which is contrary to the body's natural posture will cause fatigue and musculoskeletal complaints so that a more natural work posture regulation is needed [5], [12].

\subsection{Fatigue}

The general body fatigue is fatigue cause by physical overload. Fatigue is a body protection mechanism to avoid further damage therefore a recovery happen on a rest time. The term of fatigue usually shows varying condition on each individual, but all of them refer to the loss of efficiency and decrease of work capacity and body endurance.

Fatigue in this research was measured using a 30 items questionnaire of rating scale. The comparability test was carried out by using the Wilcoxon test by comparing the average fatigue in period 1 with period 2 before working. Meanwhile, to determine the effect of treatment is done by comparing the average fatigue in period 1 with period 2 after work. The results of the analysis show on the Table 5 below.

Table 5. Fatigue Analysis Results

\begin{tabular}{ccccccc}
\multicolumn{7}{c}{ Table 5. Fatigue Analysis Results } \\
\hline \multirow{2}{*}{ Variabel } & \multicolumn{2}{c}{ Periode I (P0) } & Periode II (P1) & \multirow{2}{*}{ Z } & \multirow{2}{*}{ P } \\
\cline { 2 - 5 } & Rerata & SB & Rerata & SB & & \\
\hline Kelelahan pre & 41.97 & 4.33 & 42,12 & 4,27 & 1,462 & 0,174 \\
Kelelahan post & 88.78 & 5.12 & 62,04 & 5,09 & $-21,364$ & 0,000 \\
\hline
\end{tabular}

Table 5 shows that in the initial condition (pre) it appears that there is no difference between period 1 and period 2 so that the subject can be stated in the same condition. Whereas in the final (post) fatigue between $\mathrm{P} 1$ and $\mathrm{P} 2$ there is a significant difference or $\mathrm{p}<0.05$. Judging from the average decrease in fatigue between period 1 (without implementation of 5S) and period 2 (with implementation of $5 \mathrm{~S}$ ) of $28.4 \%$.

This study results are in line with other studies that require ergonomic interventions to reduce fatigue and increase employee productivity [13]. The application of ergonomics is proven to reduce fatigue, subjective complaints, reduce absenteeism and improve the smoothness of service to hotel employees. These repairs can be very simple at low cost, especially since planning, but can also require a large amount of money if they have to repair the existing ones [14], [15]. There is a need of intervention in form of work system change to reduce the fatigue level of the workers [16], and the research about work model based on ergonomic principles which shows that the model can decrease fatigue [17].

\subsection{Work Productivity}

The productivity review that brought humans serious attention has recently begun to develop. The production components involved are materials (raw materials), work equipment, work systems (including 5S), supporting facilities, physical and human work environments into the ongoing work process which is the result of an ergonomic thinking study.

The measure of the success of the production process is usually expressed in terms of productivity or the ratio of output per input produced, multiplied by the time to get the output. 
In this case, human performance is the main factor determining efforts to increase productivity [18]. The main factors that influence efforts to increase productivity include technical and non-technical factors.

Hotel employee work productivity is obtained from the comparison between the amount of work that can be completed with the work rate multiplied by the work time required. Before testing the difference in significance between each treatment, the work productivity data was normality tested using test of the Shapiro-Wilk. From the results of the normality test, it was found that $\mathrm{p}>0.05$ or the data were normally distributed. To determine the effect of the treatment, the mean difference test was carried out between each group (P1 and P2) using the pair t-test. The analysis results are shown in Table 6 below.

Table 6. Analysis of Hotel Employee Productivity

\begin{tabular}{ccccccc}
\hline \multirow{2}{*}{ Variable } & \multicolumn{7}{c}{ Period P1 } & \multirow{2}{*}{ Period P2 } & \multirow{2}{*}{ t } & p \\
\cline { 2 - 5 } & Mean & SB & Mean & SB & & \\
\hline Work producti-vity & 0,0105 & 0,0021 & 0,0139 & 0,0042 & 38,145 & 0,000 \\
\hline
\end{tabular}

Table 4 shows that the work productivity of hotel employees has $\mathrm{p}<0,05$ or a significant difference between P1 and P2. Judging from the average work productivity, there was an increase of $32.5 \%$.

$5 \mathrm{~S}$ can increase work productivity because the work done by employees is more effective, the work time is faster, and the workload is lighter. Work productivity is very important in a company. There needs to be an assessment of work productivity in accompany, so there need to be an intervention to increase employee productivity. $5 \mathrm{~S}$ is in line with ergonomics principles. Ergonomic intervention with $5 \mathrm{~S}$ applications is very much needed in industries including the hospitality industry. Intervening in industrial ergonomics will increase production and productivity of worker [8], [19]. Ergonomics intervention to improvement work system its needed to increase productivity [18]. Applications of ergonomic can improve work performance and have a good effect on the health of workers [20].

\section{Conclussion}

From the results of the analysis and discussion above, it can be concluded that the implementation of $5 \mathrm{~S}$ can reduce workload (15.1\%), Musculoskeletal disorders (25.4\%) and general fatigue $(28.4 \%)$ of hotel employees. $5 \mathrm{~S}$ can also increase the work productivity of hotel employees (32.5\%). For that it is suggested that $5 \mathrm{~S}$ implementation needs to be done in housekeeping, especially in the pantry section.

\section{References}

[1] S. Liladrie, 'Do not disturb / please clean room': hotel housekeepers in Greater Toronto," Race Class, SAGE J., vol. 52, no. 1, pp. 57-69, Jul. 2010.

[2] D. S. Korkut, N. Cakıcıer, E. S. Erdinler, G. Ulay, and A. M. Dogan, "5S activities and its application at a sample company", African J. Biotechnol, vol. 8, no. 8, pp. 1720$1728,2009$.

[3] S. Sorooshian, M. Salimi, S. Bavani, and H. Aminattaheri, "Experience of $5 \mathrm{~S}$ Implementation", J. Appl. Sci. Res., vol. 8, no. 7, pp. 3855-3859, 2012.

[4] S. J. Pocock, Clinical trials: a practical approach. John Wiley \& Sons, 2013. 
[5] K. H. E. Kroemer and E. Grandjean, Fitting The Task To The Human, Fifth Editione, A Textbook Of Occupational Ergonomics. London: CRC Press, 2009.

[6] K. Schultz and J. J. Galante, "Ergonomic guidelines for manual material handling," 8th Annu. Appl. Ergon. Conf. Proc., pp. 1021-1060, 2005.

[7] M. E. Sehl and F. E. Yates, "Kinetics of Human Aging, I. Rates of Senescence Between Ages 30 and 70 Years in Healthy People", Journals Gerontol. Ser. A, vol. 56, no. 5, pp. B198-B208, 2001.

[8] A. Manuaba, “Accelerating OHS-Ergonomics Program By Integrating 'Built-In' Within The Industry's Economic Development Scheme Is A Must-With Special Attention To Small And Medium Enteprises (SMEs)", in Proceedings the 21st Annual Conference of The Asia Pasific Occupational Safety \& Health Organization, 2005.

[9] J. Dul and B. Weerdmeester, Ergonomics For Beginners, A Quick Reference Guide, Second Edition, 3rd ed. London: Taylor \& Francis, 2008.

[10] M. Yusuf, "Design of Jewel Stone Sharpener to Increase Jewel Worker Work Productivity in Bali", in International Conference on Engineering, Technology, and Industrial Application (ICETIA), 2014, pp. 353-357.

[11] T. Budiyanto, N. Adiputra, I. D. P. Sutjana, and K. Tirtayasa, "Application of RULA analysis on work posture improvement to reduce workers' fatigue and musculoskeletal complaints and to accelerate processing time of wok molding", Int. Res. J. Eng. IT Sci. Res., vol. 5, no. 4, pp. 8-15, 2019.

[12] R. S. Bridger, Introduction to Ergonomics, 3rd Edition. London: Taylor \& Francis, 2008.

[13] A. Manuaba, "Research and application of ergonomics in developing countries, with special reference to Indonesia", Indones. J. Ergon., vol. 1, no. 1, pp. 24-30, 2000.

[14] D. P. Sutjana, "Application of Ergonomics at the Bali Sanur Bungalows Hotel," Indones. J. Biomed. Sci., vol. 2, no. 1, pp. 1-11, 2008.

[15] N. D. Irwanti, M. Yusuf, N. Y. Anggreni, and L. S. Widiastuty, "Workload Analysis of Front Office Staff at Water Mark Hotel And SPA Jimbaran-Bali", Int. J. Multidiscip. Educ. Res., vol. 7, no. 8(1), p. 63, 2018.

[16] HSE, Ergonomics and human factors at work: A brief guide. 2013.

[17] M. Edem, E. Akpan, and N. Pepple, "Impact of Workplace Environment on Health Workers," Occup. Med. Heal. Aff., vol. 05, no. 02, 2017.

[18] A. Manuaba, "Total approach is a must for small and medium enterprises to attain sustainable working conditions and environment, with special reference to Bali, Indonesia", Ind. Health, vol. 44, no. 1, pp. 22-26, 2006.

[19] I. M. A. Santiana and M. Yusuf, "Design of Arrangement of Working Time to Increase Productivity of the Workers by Using Flat Iron at Garment A", Log. J. Ranc. Bangun dan Teknol., vol. 20, no. 1, pp. 35-39, 2020.

[20] E. P. L. . Kasper, 'Design of systems for productivity and well being', J. Appl. Ergon., vol. 45, no. 1, pp. 26-32, 2014. 